\title{
An Intelligent Logistics Management Model in Prefabricated Construction
}

\begin{abstract}
In recent years, with the increasingly complex fabricated construction environment and increasingly challenging logistics management requirements, this paper proposes a model of intelligent logistics management based on radio frequency identification and building information modeling, which enables monitoring full life cycle of building components and improving construction efficiency through real-time uploading and tracking components and materials logistics information. The empirical model was typically used in the construction of a major theme park with good results achieved.
\end{abstract}

Keywords: logistics management, intelligent construction, BIM, RFID, fabricated construction, major theme park

\section{Introduction}

In the context of promoting green construction, the idea of industrialized building based on prefabricated construction came into people's visual field. Prefabricated construction, as the name suggests, is prefabricating various components in the factory: Wallboards, stairs, balconies, decorative objects, etc., and then transport the components to the construction site for assembly. Such construction technology has many advantages: 1) Achieving mass production of buildings; 2) improving construction quality; 3) reducing the duration and cost (Shi, Tang, \& Zhang, 2014). Meanwhile, in prefabricated construction, component factory and assembling site are separate from each other with a certain distance. As a result, distribution has become a key determinant for the efficiency of prefabricated construction.

Manuscript received February 27, 2015; accepted June 5, 2015

Chong-guang Feng ( $₫$ )

Sino-US Global Logistics Institute, Shanghai Jiao Tong University, Shanghai 200030, China

Email: fengchongguang@126.com

Hao $\mathrm{Hu}$, Feng $\mathrm{Xu}$, Jian Yang

School of Naval Architecture, Ocean \& Civil Engineering, Shanghai Jiao Tong University, Shanghai 200240, China
In particular, for large-scale international theme park led by international company, many single buildings with complex structure are built at the same spot, thus a wide variety of materials are needed. Engineering standards, safety requirement and environmental protection criterion are quite stringent. Several factors combined together put forward higher requirements on logistics and transportation accuracy, timeliness and security. Therefore, applying modern electronic information technology to carry out intelligent logistics management for complex fabricated construction project, would be a significant issue to be studied.

In recent years, scholars from home and abroad have conducted in-depth research on intelligent logistics management of construction projects. Irizarry, Karan, \& Jalaei (2013) combined building information modeling (BIM) and geographic information systems (GIS) to create a comprehensive model for tracking the status of the construction project supply chain and materials distribution; Suchart (2003) applied wireless network and other information technology in logistics visualization of logistics in construction projects to improve quality and efficiency; Yoon \& Chin (2011) used radio frequency identification (RFID) technology and BIM technology in building materials logistics and noted that it had broad application prospects both in terms of cost control and improving engineering efficiency.

Domestic research made many achievements in this field as well. Su (2014) conducted research on prefabricated component full life cycle tracking based on RFID technology; Li (2011) investigated the application cases of BIM and RFID technology in prefabricated construction, and proposed real-time monitoring, schedule simulation and other solutions in logistics; $\mathrm{Hu}$ (2013) explored the application of Zigbee technology and RFID technology in material distribution and inventory management in discrete manufacturing industries.

Current research results have some reference value for intelligent logistics management. However, for large-scale international theme park construction project, shortages of two aspects emerge gradually:

Firstly, a lack of instances of relating project progress 
management and real-time logistics management to field control. Existing research results are mostly concerned with one aspect of project management. This article fully considers the characteristics of fabricated construction and combines logistics management and field control closely together to adopt just-in-time into industrial buildings production.

Secondly, there exists a shortage of research findings focusing on intelligent logistics management in large assembled construction project. In large-scale international theme park, as the building structure is complex and component amount is significant, construction site management is more difficult. This article provide practical application cases of dynamic updating and monitoring logistics status and BIM design drawings, which would fill in the vacancy in the study of this field.

\section{Intelligent logistics management model in prefabricated construction}

Based on practical experience of large scale prefabricated construction projects, this article promotes an integrated intelligent logistics management model for large scale projects. Figure 1 is the schematic diagram of the model. This logistics management system regards project management headquarters and its data center as the core. It works in close conjunction with project timelines and controls the prefabricated construction process, with the benefit of both integrated logistics data processing and real-time logistics scheduling.

This model applies Primavera 6.0 (P6) project management software and BIM and introduces RFID technology and mobile terminal. Its functionality includes uploading and tracking component logistics information, monitoring whole lifecycle of building components, and improving working efficiency of prefabricated construction.

\section{Actual application validation}

This article takes a large theme park engineering practice as an example to introduce the application and feasibility of this model.

The theme park project used P6 as a basis for developing the construction schedule. In the schedule table in P6, the required project resources, working hours, cost and other information were very clear. Logistics has always been throughout the whole project and interspersed at every step of implementation of individual buildings. Project management department arranged workloads in each stage according to schedule, and then calculated the amount of material needed based on the project. According to a material distribution plan, they determined the purchase,

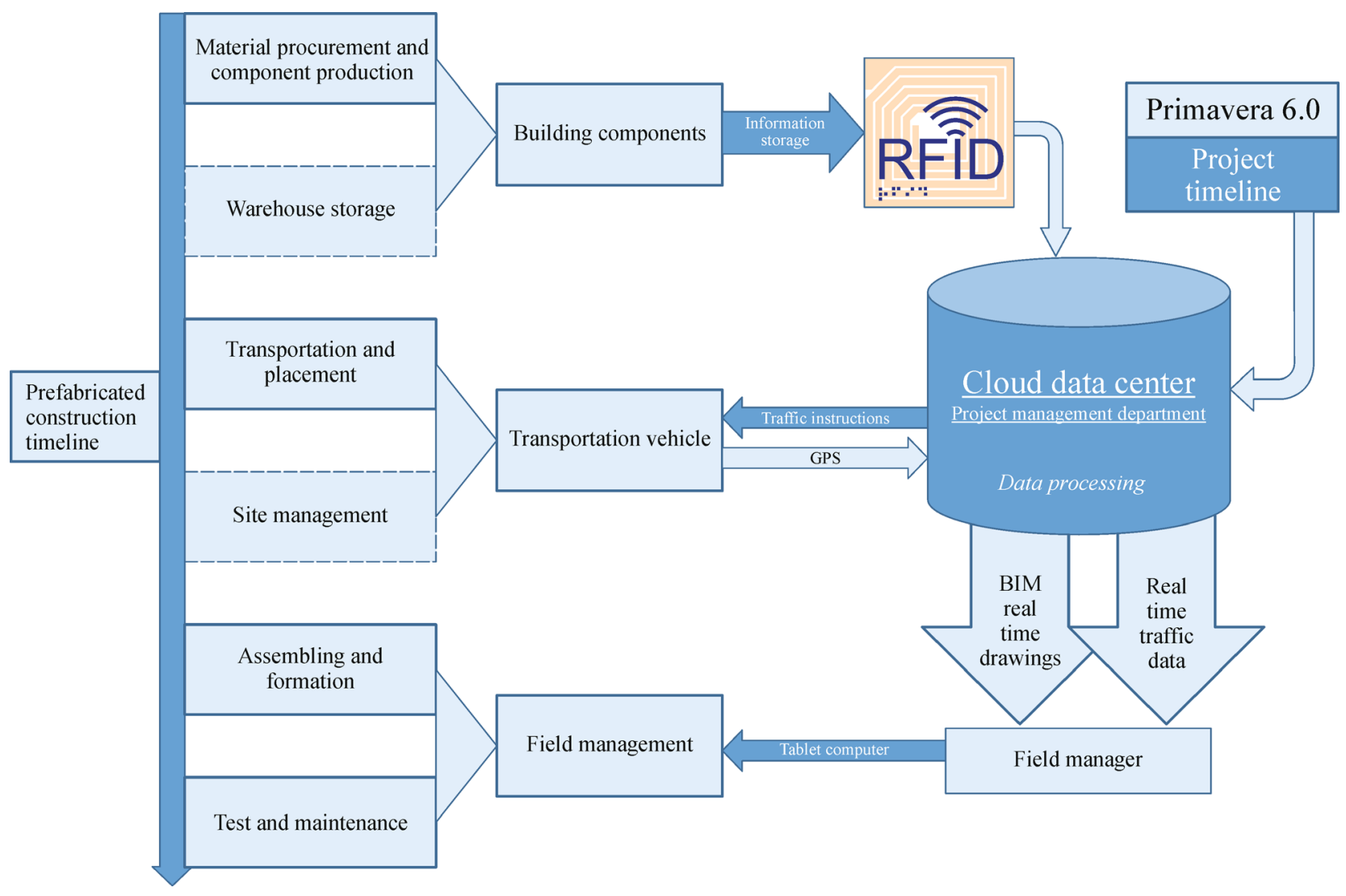

Figure 1. Prefabricated construction intelligent logistics management architecture model. 
processing and production plans.

During the project logistics management, large-scale of the RFID tags were used to achieve information collection and uploading. Active RFID technology is a non-contact automatic identification technology that consists of data collection terminal, tags, readers, antennas, and application systems. Active RFID is widely used for its basic features: Simple structure, small size, low cost, low power consumption, and long-distance transmission. Its basic principle is identifying object to carry information extraction and automatic identification by radio frequency signal transmission characteristics of spatial coupling (Qiao, 2014), which provides us a connecter between objects and the Internet interface, so that the objects were linked together.

For any building component, its life cycle includes procurement and production, warehouse storage, transportation, assembling and formation, test and maintenance. By setting a RFID tag on the component, project managers could achieve the purpose of supervision and control during warehousing, transportation and assembling. In the procurement and production processes, workers encoded the components by a unique number, then uploaded a package including processing, distribution, assembling information such as acceptance confirmation, worksheet, logistics, on-site installation instruction into an active RFID chip to track member status and prepare for the next step.

The theme park project component processing factory was located $5 \mathrm{~km}$ away from the construction site. When processing was completed, according to the schedule, they should arrange specific material transportation. Project engineers installed two transmitters at the theme park entrance, called Terminal A and Terminal B. When the material traffics came into the construction site by the entrance, the computer displayed "from A to B", and recorded the status of the components and the arrival time. Similarly, when the material traffics left, the computer displayed as "B to A", and recorded the relevant data. Meanwhile, the recorded information would be instantly uploaded to the cloud data center and the location information of the vehicles would also be uploaded to the data center by global satellite positioning system. Material transportation vehicles would travel through exclusive transportation lanes in the construction site, and project managers could issue their instructions based on traffic conditions. The vehicle location and transport speed will also provide a reference for project managers.

Factory processing, transportation and on-site assembling, these steps are all linked with one another. As a consequence, organizational efficiency of logistics directly affects the time interval between each step. When the project introduced active RFID technology, component location and status were quickly uploaded to the Internet and the hands of various managers, thus greatly improved construction efficiency. In this case, warehouse storage and on-site stacking materials almost disappeared. There was no need to clean up a special site stacking field, and inventory cost was close to zero. This project approximately reached just-in-time industrial production standard.

Project management staff used tablet personal computers and other mobile terminal receiving real-time logistics information, and directed the construction site according to downloaded BIM model. With real schematic diagram in hand, assembly areas, machinery positioning, transport traffic and construction sequence all became very intuitive for the managers. Applying mobile terminal in site management helped project managers receive and upload the site drawings, processing, transportation and distribution data, thus greatly improved the convenience and accuracy of management. In the follow-up inspection and maintenance step, engineers could easily replace or repair questionable components based on the serial number and RFID record. They could even explore the causes and related responsibilities concerning the questionable components by retroactivity.

Active RFID tags have decent reusability. Currently, for large projects that require lots of tags, the cost might be a bit high. In consideration of technological development, active RFID tag prices are rapidly declining. In the near future, many fabricated construction sites should adopt active RFID in project management at a more economical price.

\section{Conclusions}

Intelligent logistics management is not only the key to improving productivity in prefabricated construction, but also the future of large-scale project logistics management. Proposition and application of prefabricated construction intelligent logistics management system, achieved good practical effect in large-scale prefabricated construction project, and accumulated valuable experience. When designing a construction project logistics management model, people should adjust measures according to local conditions and comprehensive analysis of the project requirement. The theme park project logistics management practices would be a good example for similar construction projects.

\section{References}

Hu, Q. (2013). An application of RFID technology in the discrete manufacturing industry complex material distribution (Dissertation for the Master's Degree). Qingdao: China Ocean University (in Chinese)

Irizarry, J., Karan, E. P., \& Jalaei, F. (2013). Integrating BIM and GIS to improve the visual monitoring of construction supply chain management. Automation in Construction, 31, 241-254 
Li, T. (2011). Prefabricated building life cycle management application of BIM and RFID (Dissertation for the Master's Degree). Dalian: Dalian University of Technology (in Chinese)

Qiao, J. (2014). RFID technology in logistics. Science and Technology Vision, 3, 5-6 (in Chinese)

Shi, J., Tang, J., \& Zhang, K. (2014). Study on and countermeasure for development of prefabricated building of Shanghai. Housing Science and Technology, 11, 1-5 (in Chinese)

$\mathrm{Su}$, C. (2014). RFID-based prefabricated housing components tracking management research (Dissertation for the Master's Degree). Harbin: Harbin Institute of Technology (in Chinese)

Suchart, N. (2003). The effects of visual-based information logistics in construction (Dissertation for the Master's Degree). Raleigh: North Carolina State University

Yoon, S., \& Chin, S. (2011). An RFID and BIM based simulator for construction material logistics and progress management. Korean Journal of Construction Engineering and Management, 12(5), 46-54 (in Korean) 